\title{
Electrochemical behaviour of platinum at polymer-modified glassy carbon electrodes
}

\author{
CARMEM L P S ZANTA ${ }^{1, *}$ and C A MARTÍNEZ-HUITLE ${ }^{2, *}$ \\ ${ }^{1}$ Departamento de Química da Universidade Federal de Alagoas, Campus A.C. Simões, \\ Tabuleiro do Martins, Maceió-AL 57072-970, Brazil \\ ${ }^{2}$ University of Milan, Department of Chemistry, Celoria 2, 20133 Milan, Italy \\ e-mail: carlos.martinez@unimi.it; clp@qui.ufal.br
}

MS received 19 April 2007; revised 24 June 2007

\begin{abstract}
In this paper, the preparations and voltammetric characteristics of chitosan-modified glassy carbon (Ct-MGC) and platinum electrodes are studied. Ct-MGC can be used for pre-concentration and quantification of trace amounts of platinum in solution. At low $\mathrm{pH}$ medium, the complex of Pt with protonated group $-\mathrm{NH}^{3+}$ in the chitosan molecule has been confirmed by FT-IR spectra studies.
\end{abstract}

Keywords. Chitosan; platinum; FT-IR spectra; platinum complex; carbon electrodes.

\section{Introduction}

The use of transition metal complexes immobilized on various support materials in catalysis combines the advantages of homogeneous and heterogeneous catalytic systems, and makes it possible to carry out processes under mild conditions with high selectivity. ${ }^{1}$ The broadening of the spectrum of support materials and processes as well as the involvement of new substrates in the reactions of heterogenized metal complexes is a problem of current interest. Biopolymers such as cellulose, chitin, and chitosan, find recent use as support materials for the heterogenization of homogeneous catalysts. ${ }^{2,3}$ Chitosan (deacetylated chitin) is a linear polysaccharide with a polymer chain consisting of $\beta$-1,4-linked glucosamine residues (figure 1).

Chitosan has unique properties that make it advantageous over other polymer support materials: ${ }^{4-6}$ (a) Chitosan is non-toxic, readily decomposes in natural biological environments, and is compatible with living organism cells (both plant and animal); (b) the polymeric matrix is capable of providing the high dispersity of a metal; (c) chitosan has various functional groups; (d) chitosan is resistant to oxidants such as air, oxygen, and can dilute hydrogen peroxide; (e) the mechanical strength of chitosan is rather high; and (f) valuable catalyst components can easily be separated from the spent catalyst by burning out the organic support and which can help further extraction of metals. The thermal stability of chitosan is not high (it decomposes at $250^{\circ} \mathrm{C}$ ), but one of the requirements of modern catalysts is their capability of operating under mild conditions. Although chitosan is broadly used in various industries, data on its applications in catalysis are currently scarce. Chitosan and chitin complexes with platinum group metals are used in the reactions of heterogeneous catalytic hydrogenation (including asymmetric hydrogenation) ${ }^{7,8}$

The peculiar properties of chitosan depend on the presence of reactive amino and hydroxyl functional groups that lead to a large hydrophilic surface. This explains why several groups have explored the pos-

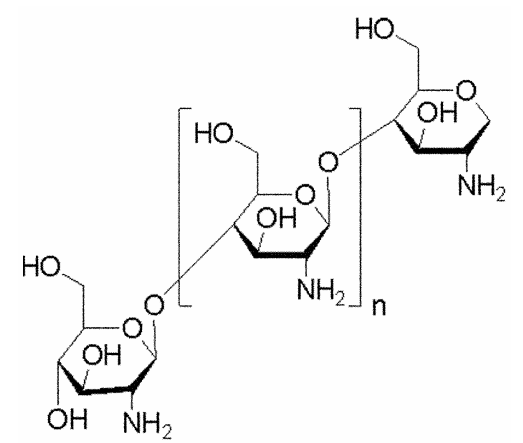

Figure 1. Structure of chitosan.

*For correspondence 
sibility of using chitosan for developing electrochemical sensors and biosensors. ${ }^{9-19}$ However, much attention has been paid to electro-analytical applications in which chitosan-modified glassy carbon or metal electrodes are used for adsorbing metal ions, ${ }^{10,11,20,21}$ organics $^{22,23}$ and anions. ${ }^{24}$

In some investigations on the electrochemical properties of chitosan-modified glassy carbon (CtMGC) electrodes, it was observed that these modified electrodes exhibit a high perm-selectivity towards Pt ions. ${ }^{14}$ This strong affinity between $\mathrm{Pt}$ and chitosan film was ascribed to the presence of two ligands around each metal ion, unlike other metals. $^{25-27}$ Thus, it seems interesting to explore the possibility of quantifying $\mathrm{Pt}$ in solution using these modified electrodes. On the other hand, the platinum particles incorporated into chitosan film may be used as catalyst layer and/or proton exchange membrane in direct alcohol fuel cells and biofuel cells. For these reasons, the platinum-chitosan modified glassy carbon electrodes obtained after incorporation of $\mathrm{Pt}$ into the chitosan film have also been tested for the electro-oxidation of alcohol.

In this paper, a modification strategy of electrodes with thin films of chitosan is described. These electrodes were used to quantify Pt in solution. Subsequently, new Pt-chitosan modified electrodes were used to study the electro-oxidation of ethanol in solution. During ethanol electrochemical oxidation, two types of chitosan films were studied: (a) chitosanmodified glassy carbon electrode and (b) chitosanmodified glassy carbon electrode and cross-linked with glutaric dialdehyde.

The cross-linking chemistry of chitosan with glutaric dialdehyde is well known ${ }^{12}$ and involves Schiff base formation according to the reaction:

$$
\begin{gathered}
\mathrm{Ct}-\mathrm{NH}_{2}+\mathrm{O}=\mathrm{CH}-\left(\mathrm{CH}_{2}\right)_{3}-\mathrm{HC}=\mathrm{O}+\mathrm{H}_{2} \mathrm{~N}-\mathrm{Ct} \rightarrow \\
\mathrm{Ct}-\mathrm{N}=\mathrm{CH}-\left(\mathrm{CH}_{2}\right)_{3}-\mathrm{HC}=\mathrm{N}-\mathrm{Ct}+2 \mathrm{H}_{2} \mathrm{O} .
\end{gathered}
$$

Cross-linking can reduce the solubility of chitosan in aqueous solvents over a broad $\mathrm{pH}$ range, and increased resistance to chemical degradation or longterm biological degradation. However, this chemical modification can change the permeability of the film.

\section{Experimental}

\subsection{Chemicals}

Chemicals of high quality were used without further purification. Chitosan (MW 1.9-3.1 $\times 10^{5}$ ) and glutaric dialdehyde $\left(25 \%\right.$ solution in $\left.\mathrm{H}_{2} \mathrm{O}\right)$ were purchased from Sigma-Aldrich. The other reagents were from Fluka. Dihydrogen hexachloroplatinate (IV) known as chloroplatinic acid $\left(\mathrm{H}_{2} \mathrm{PtCl}_{6}\right)$ were employed as commercial standard solutions (1000 ppm). Aqueous solutions were prepared using double-distilled deionised water and purged with nitrogen gas prior to each experiment.

\subsection{Equipment}

Cyclic voltammetric (CV) experiments were carried out with an Autolab PGSTAT30 (EcoChemie), connected to a PC. The three-electrode cell assembly consisted of a modified glassy carbon working electrode ( $2 \mathrm{~mm}$ diameter, Metrohm), an $\mathrm{Ag} / \mathrm{AgCl} / \mathrm{Cl}^{-}(3 \cdot 0 \mathrm{M})$ reference electrode and a platinum wire counter electrode. All the potentials are reported versus the above specified reference electrode.

Differential pulse voltammetric parameters for $\mathrm{Pt}$ calibration curves were as follows: purge time: $5 \mathrm{~min}$, equilibration time: $10 \mathrm{~min}$, pre-concentration time: $1 \mathrm{~min}$, potential scan rate: $10 \mathrm{mV} \mathrm{s}^{-1}$, pulse amplitude: $100 \mathrm{mV}$ and pulse width: $50 \mathrm{~ms}(0.05$ $\mathrm{M} \mathrm{H}_{2} \mathrm{SO}_{4}$ ). The experiments were conducted at room temperature $\left(22 \pm 2^{\circ} \mathrm{C}\right)$ under $\mathrm{N}_{2}$ atmosphere. Calibrations were analysed by ordinary linear least-square regression and the relevant results (slopes and intercepts) reported with their confidence interval $(P=95 \%)$.

\section{$2.3 C t-M G C$ electrodes preparation}

2.3.a Chitosan solution: Different chitosan stock solutions were prepared in this study.

Solution 1: $0.02 \mathrm{~g}$ chitosan were dissolved in $10 \mathrm{~mL}$ of $2.0 \mathrm{M}$ acetic acid solution. ${ }^{11,19-24}$

Solution 2: $0.02 \mathrm{~g}$ chitosan were dissolved in $10 \mathrm{~mL}$ of $2.0 \mathrm{M}$ acetic acid solution. ${ }^{11,19-24}$ Subsequently, this solution was added with $3.5 \mathrm{~mL}$ of $25.0 \mathrm{wt} \%$ glutaric dialdehyde solution ${ }^{12-16}$ and homogenized by stirring for $10 \mathrm{~min}$.

\subsection{Preparation of the modified electrodes}

The surface of glassy carbon (GC) electrodes was first polished with alumina slurry and sonicated with deionized water for $5 \mathrm{~min}$. After sonication, electrodes were rinsed with deionized water and allowed to dry. 
The electrodes were then surface-modified by depositing with a microsyringe $6.0 \mu \mathrm{l}$ of a given chitosan stock solution. Ct-GCE $\mathrm{AcOH}_{\mathrm{H}}$ and $\mathrm{Ct}-\mathrm{GCE}_{\mathrm{ga}}$ indicate glassy carbon electrodes modified by depositing solution 1 or 2 , respectively. All the electrodes were left to dry in air for $30 \mathrm{~min}$. Before use, Ct-MGC electrodes were equilibrated for about $10 \mathrm{~min}$ in the supporting electrolyte solution ( $\left.0.05 \mathrm{M} \mathrm{H}_{2} \mathrm{SO}_{4}\right)$.

\section{Results and discussion}

\subsection{Cyclic voltammetric experiments}

3.1a Base voltammograms in sulphuric acid supporting electrolyte: According to literature, ${ }^{28,29}$ the protonation of amine groups is responsible for dissolving chitosan in many acidic solutions, with the exception of sulphuric acid. The experiments were therefore carried out in sulphuric acid as supporting electrolyte $\left(0.05 \mathrm{M} \mathrm{H}_{2} \mathrm{SO}_{4}\right)$. Figure 2 shows the behaviour of the modified electrodes and bare GCE in the chosen supporting electrolyte. Voltammograms obtained at a bare GCE showed a reversible redox system around $0.35 \mathrm{~V}$, likely due to redox surface processes.$^{30}$ However, this feature is almost imperceptible in the figure due to the scaling factor necessary to accommodate all other voltammograms.

Chitosan-modified electrodes (curves 2 and 3) exhibit a slightly larger peaks separation, which can be possibly explained by partial protonation of polymer terminal groups in the presence of $\mathrm{H}_{2} \mathrm{SO}_{4}{ }^{29,30}$ and/or GCE surface oxidation processes such as those observed in Nafion coated GCE voltammetric behaviour. ${ }^{31} \mathrm{Ct}^{-\mathrm{GCE}_{\mathrm{ga}}}$ (curve 3) is characterized by a

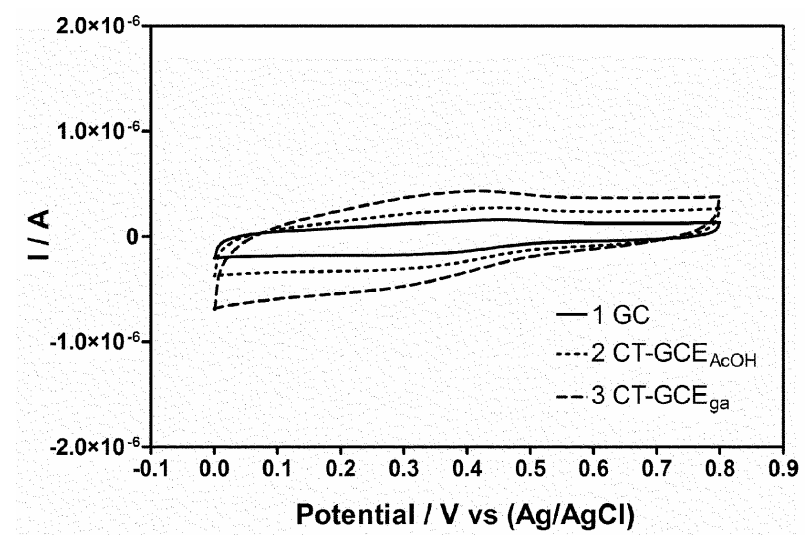

Figure 2. Cyclic voltammograms at the GC and chitosanmodified $\mathrm{GC}$ electrodes in $0.05 \mathrm{M} \mathrm{H}_{2} \mathrm{SO}_{4}$ as supporting electrolyte; scan rate $100 \mathrm{mV} \mathrm{s}^{-1}$. large current increase with respect to the bare GCE resulting from permeability changes. In fact, the cross-linking chemistry of chitosan with glutaric dialdehyde (GA) is well known ${ }^{12}$ and involves Schiff base formation. This chemical modification produces a decrease of density of free amine groups at the surface of the sorbent film, followed by decrease of polymer permeability towards cations and anions. Ct-GCE $E_{\mathrm{AcOH}}$ presented a large current increase with respect to the bare electrode; even if slightly lower than that of the Ct-GCE $E_{\text {ga }}$. This effect could also be explained by considering zone decrease of the permeability.

$3.1 \mathrm{~b}$ Voltammograms in the presence of Pt solution: Ct-MGC electrodes were first immersed in an electrochemical cell containing a $0.1 \mathrm{M} \mathrm{H}_{2} \mathrm{PtCl}_{6}$ (Aldrich) solution during $15 \mathrm{~min}$. After incorporating $\mathrm{PtCl}_{6}^{2-}$, the electrodes were rinsed for $5 \mathrm{~s}$ in $0.05 \mathrm{M} \mathrm{H}_{2} \mathrm{SO}_{4}$ solution and dried. The $\mathrm{PtCl}_{6}^{2-} /$ chitosan electrode was placed in an electrochemical cell and polarized at $0.05 \mathrm{~V}$ for $1 \mathrm{~min}$. The electrolytic solution was an aqueous solution of $0.05 \mathrm{M}$ $\mathrm{H}_{2} \mathrm{SO}_{4}$. This procedure yields metallic platinum inside the chitosan matrix. However, this result is mainly due to the combination of two effects: the chelatingchitosan properties and potential application.

Figure 3 shows the voltammetric cycles at both $\mathrm{CG} / \mathrm{Ct} / \mathrm{Pt}$ electrodes (with and without GA) at $10 \mathrm{mVs}^{-1}$. The electroreduction from $\mathrm{PtCl}_{6}^{2-}$ to $\mathrm{Pt}$ is confirmed by the typical hydrogen adsorption/ desorption profile of platinum electrodes, ${ }^{32}$ in the potential range below $0.3 \mathrm{~V}$. It is thus important to

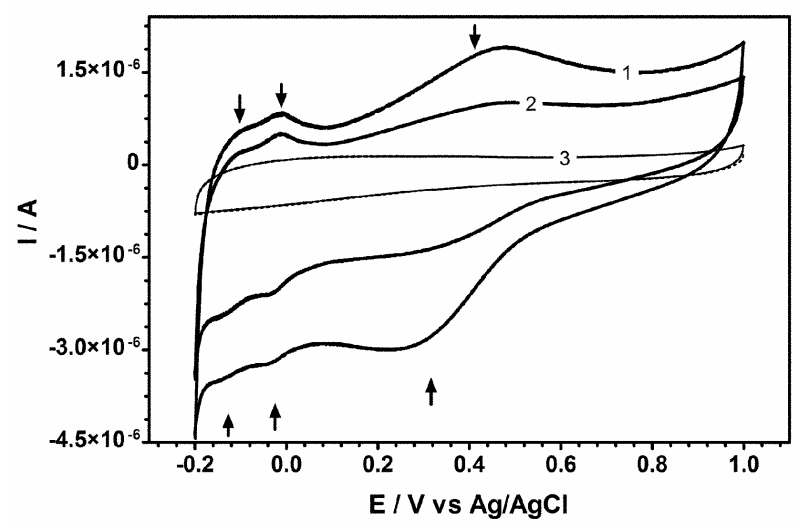

Figure 3. Cyclic voltammograms at (1) $\mathrm{CG} / \mathrm{Ct} / \mathrm{Pt}$; (2) $\mathrm{CG} / \mathrm{Ct} / \mathrm{Pt}$ cross-linked with GA and (3) Ct-MGC electrode. Curves 1 and 2 indicate the typical hydrogen adsorption/desorption areas of $\mathrm{Pt}$ electrode. Pt loading: $0.979 \mathrm{mg}$. 
note that the adsorption/desorption profiles reported in figure 3 depend on Pt loading into $\mathrm{Ct}$ film; however these profiles are well-defined as reported by Cogo et al. ${ }^{33}$

The formation of platinum on the substrate demonstrates that the $\mathrm{Ct}$ film acts as a biodegradable catalyst support. The $\mathrm{CG} / \mathrm{Ct} / \mathrm{Pt}$ electrode displays stable potentiodynamic responses under the conditions employed, as demonstrated by the small difference between the first and final voltammograms. The complexity between $\mathrm{Ct}$ and metallic particles makes them fixed in the host matrix. Nevertheless, this complexity probably blocks some platinum sites for hydrogen adsorption/desorption, which is the reason for the less defined redox pair about $-0 \cdot 15 \mathrm{~V}$. On the other hand, at $\mathrm{CG} / \mathrm{Ct} / \mathrm{Pt}$ electrode (curve 1, figure 3) shown more well-defined Pt adsorption/desorption peaks than $\mathrm{CG} / \mathrm{Ct} / \mathrm{Pt}$ electrode cross-linked with GA (curve 2, figure 3). The $-\mathrm{NH}_{2}$ group of chitosan is protonated in low $\mathrm{pH}$ solution. Based on the above results, the electrode processes can be compared and agree with the results proposed by Ye et $a l^{11}$.

\subsection{Mechanism of adsorption of Ct}

In acidic media, the free amino group $\left(-\mathrm{NH}_{2}\right)$ in $\mathrm{Ct}$ is protonated $\left(-\mathrm{NH}_{3}^{+}\right)$. The reaction could be represented by the following equation:

$$
\mathrm{R}-\mathrm{NH}_{2}+\mathrm{H}_{2} \mathrm{O} \rightarrow \mathrm{R}^{-\mathrm{NH}_{3}}{ }^{+}+\mathrm{OH}^{-} \text {. }
$$

According to the static gravitation, $\mathrm{Ct}$ with positive charge can adsorb anions of charge neutralization exists in acid solution in anion group forms $\left(\mathrm{PtCl}^{4}\right)$, hence Pt (IV) can be strongly adsorbed by Ct. Figures $4 \mathrm{a}$ and $\mathrm{b}$ show the FT-IR spectra of $\mathrm{Ct}$ before and after adsorption for Pt (IV) respectively. The characteristic absorption peaks of amino and hydroxyl is at $3387 \mathrm{~cm}^{-1}$, carbonyl of amide is at $1662 \mathrm{~cm}^{-1}$, and secondary alcohol and primary alcohol is at 1067 and $1025 \mathrm{~cm}^{-1}$, respectively. Compared with the IR spectrum of $\mathrm{Ct}$ before adsorption, it can be seen that the main adsorption peaks $\left(-\mathrm{NH}_{2}\right.$ and $-\mathrm{OH})$ of $\mathrm{Ct}$ did not change. The results indicate that the action between $\mathrm{Ct}$ and Pt (IV) is mainly due to the formation of a complex by strong interaction between $\mathrm{Ct}$ and $\mathrm{Pt}$.

\subsection{Application of Ct-modified electrode for Pt determination}

Preliminary measurements at Ct-MGC films were performed using differential pulse voltammetry technique for improving the sensitivity (figure 5). These experiments have also been carried out to show the affinity and capacity of $\mathrm{Ct}$ towards the Pt. Data obtained analysing Pt standard solutions in the chosen medium, allowed estimating the functional relationship (peak current $v s$ concentration). A linear range between the peak current and Pt conc. was obtained (inset figure 5). The comparison of the electrochemical behaviour of Ct-MGC and bare electrode allows highlighting the advantages of the modified electrode.

These results helped in allowed estimating few calibration diagrams of $\mathrm{Pt}$ at different $\mathrm{Ct}$-MGC electrode, obtained by considering at least ten concentrations of $\mathrm{Pt}$ and evaluating the peak intensity as a function of Pt concentration. The visual analysis of the residuals of the regression allowed estimating a linear range spanning from $2.26 \times 10^{-6}$ to $7 \cdot 18 \times$ $10^{-6} \mathrm{~mol} \mathrm{~L}^{-1}$. Few examples of the relevant regression functions are shown in table 1 . As can be seen the determination coefficients are always larger than 0.99 . However, the results in table 1 show a certain variability of slopes and intercepts. This is not surprising since it is known ${ }^{8}$ that responses at polymer modified electrode strongly depend on the actual status of their electrode surface.

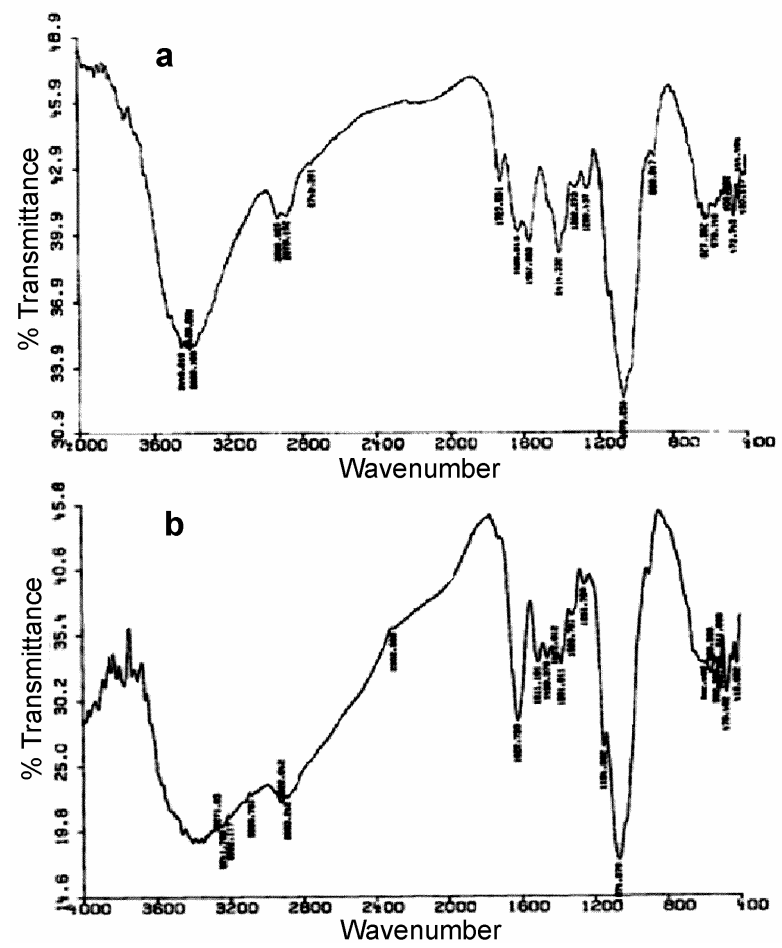

Figure 4. The FT-IR spectra (a) $\mathrm{Ct}$ before adsorption (b) $\mathrm{Ct}$ after adsorbed $\mathrm{Pt}$. 
Table 1. Response-concentration functional relationships obtained at different CtMGC electrodes as a function of Pt concentrations.

\begin{tabular}{lcc}
\hline Regression line & Degrees of freedom & $r^{2}$ \\
\hline$I=(1.0313 \pm 0 \cdot 0224) C+(4 \cdot 3083 \pm 1 \cdot 147) \times 10^{-7}$ & 8 & 0.9996 \\
$I=(1.0325 \pm 0.0235) C+(4 \cdot 2977 \pm 1 \cdot 195) \times 10^{-7}$ & 8 & 0.9998 \\
$I=(1.0301 \pm 0.0215) C+(4 \cdot 3169 \pm 1 \cdot 186) \times 10^{-7}$ & 8 & 0.9994 \\
\hline
\end{tabular}

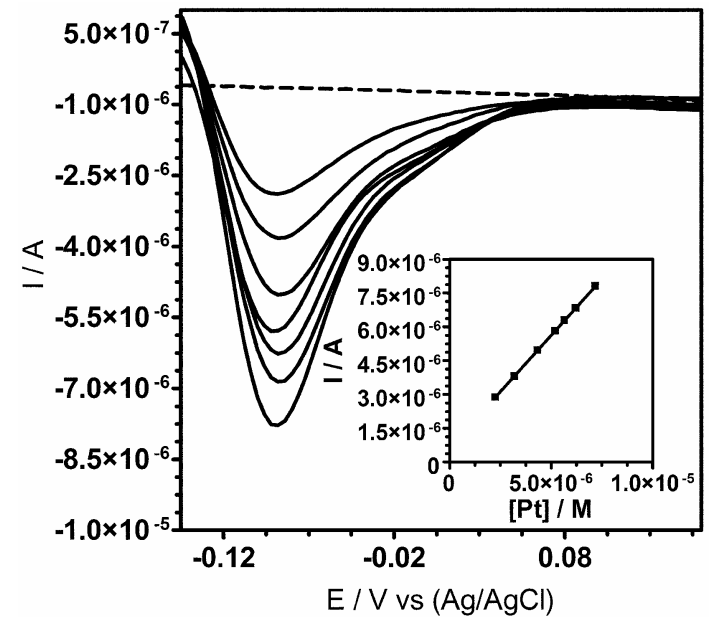

Figure 5. Differential pulse voltammograms at $\mathrm{Ct}$ MGC electrode, recorded in $0.05 \mathrm{M} \mathrm{H}_{2} \mathrm{SO}_{4}$ containing different Pt concentrations.

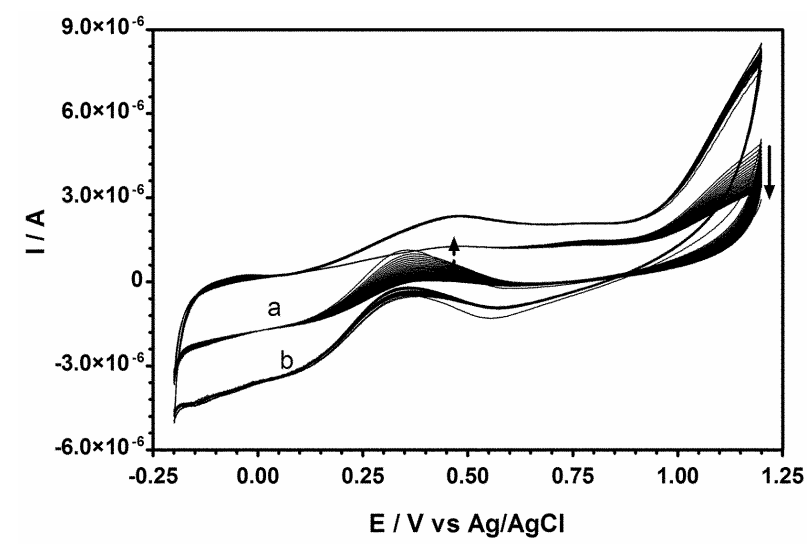

Figure 6. Cyclic voltammograms in presence of ethanol $1 \times 10^{-3} \mathrm{M}$ in $\mathrm{H}_{2} \mathrm{SO}_{4} 0.05 \mathrm{M}$ at: (a) $\mathrm{CG} / \mathrm{CT} / \mathrm{Pt}$ and (b) $\mathrm{CG} / \mathrm{CT} / \mathrm{Pt}$ cross-linked with GA.

A preliminary estimation of the limit of detection (LOD), was also possible using the approach based on the standard deviation of the regression, $s_{\mathrm{y} / \mathrm{x}}$, (for a recent review on LOD approaches) ${ }^{34}$

$$
\mathrm{LOD}=\frac{3 \cdot 0 s_{y / z}}{b}
$$

where $S_{y / x}$ is the residual standard deviation and $b$ the slope of the calibration plot. This approach allows controlling both types I and II errors at 5\%. According to these preliminary results, the LOD range can be determined at about $3.5 \times 10^{-8}$.

\subsection{Application of Pt/Ct-modified electrode for ethanol oxidation}

After Pt incorporation into chitosan film, the new $\mathrm{Pt} / \mathrm{Ct}-\mathrm{MGC}$ electrodes were tested for electrooxidation of ethanol. Cyclic voltammograms at Pt-modified electrodes were recorded in presence of $1 \times 10^{-3} \mathrm{M}$ ethanol in acidic media $\left(0.05 \mathrm{M} \mathrm{H}_{2} \mathrm{SO}_{4}\right)$, and during the anodic scan displays a higher anodic current in the range 0.1 to $0.5 \mathrm{~V}$ was attained compared with the base electrolyte. As observed in figure 6, two regions can be considered during the positive potential cycle of electrodeposited $\mathrm{Pt}$ in $1 \times 10^{-3} \mathrm{M}$ ethanol solution in the base electrolyte at both electrodes (curve $\mathrm{a}$ and $\mathrm{b}$ ); the first one corresponding to the dehydrogenation of alcohol $(0.31$ to $0.57 \mathrm{~V}$ potential range) and the second one associated with bulk oxidation of ethanol $(E>0.8 \mathrm{~V})$.

During the electro-oxidation of ethanol, the appearance of two peaks on the anodic sweep may be ascribed to the oxidation of the fuel by two kinds of chemisorbed oxygen species. ${ }^{35,36}$ On the cathodic return sweep the electrode surface may be completely covered with oxygen and renewed oxidation of the fuel can only begin after a part of the oxygen layer has first been reduced. ${ }^{36,37}$ The oxidation peak in the cathodic sweep is thus displaced in the direction of the hydrogen potential.

On the other hand, an increase in the oxidation current above $0.85 \mathrm{~V}$ is observed at both $\mathrm{CG} / \mathrm{Ct} / \mathrm{Pt}$ electrodes, and it decreases in relation to decrease in ethanol concentration in solution. This behaviour indicates a poisoning of catalyst sites with increasing alcohol concentration due to the adsorption of alcohol on catalyst surface.

Finally, CG/Ct/Pt electrode cross-linked with GA (curve b) is characterized by lower electro-activity during ethanol oxidation with respect to $\mathrm{CG} / \mathrm{Ct} / \mathrm{Pt}$ 
electrode (curve a), probably resulting from permeability change due to cross-linking chemistry of chitosan-GA ${ }^{12}$ which blocks some platinum sites.

Even though results seem to show that the electrochemical oxidation of ethanol at Pt/Ct-MGC electrodes was achieved, and these modified electrodes show a strong cycle dependence, further studies about intermediates are needed to determine the ethanol electro-oxidation efficiency.

\section{Conclusions}

Cyclic voltammetric studies showed that chitosan has a wider range of potential window in positive potential with complexity capacity groups. It is ideal when used as the modified reagent for $\mathrm{Ct}-\mathrm{MGC}$ to determine precious elements such as Pt. These properties were confirmed by cyclic voltammetry in the presence of Pt in solution and FT-IR studies of $\mathrm{Ct}$ film before and after adsorption for Pt. On the other hand, during quantification of $\mathrm{Pt}$ in solution by differential pulse technique using Ct-MGC electrodes, a linear range and limit of detection, $2.26 \times 10^{-6}$ to $7.18 \times 10^{-6} \mathrm{~mol} \mathrm{~L}^{-1}$ and $3.5 \times 10^{-8} \mathrm{~mol} \mathrm{~L}^{-1}$, can be determined respectively. On the basis of voltammetric studies during ethanol electro-oxidation at $\mathrm{CG} /$ $\mathrm{Ct} / \mathrm{Pt}$ electrodes, we conclude that chitosan modification with Pt may be used as proton exchange membrane for micro fuel cells. We have also demonstrated that films of chitosan serve as catalyst support for Pt particles leading to stable and electroactive results. However, detailed studies will be performed using spectrochemical techniques to identify the adsorbed intermediates and elucidate the reaction mechanism and possible applications of these electrodes in the field of energy conversion.

\section{References}

1. Hirao T, Higuchi M, Hatano B and Ikeda I 1995 Tetrahedron Lett. 365925

2. Kaneda K, Yamamoto H, Imanaka T and Teranishi S 1985 J. Mol. Catal. 2999

3. US Patent 43673551983

4. Yang J H and Vigee G S 1991 J. Inorg. Biochem. 417

5. Chiessi E and Pispisa B 1994 J. Mol. Catal. 87177

6. Chernetskii V N and Nifant'ev N E 1997 Rossiiskii Khimicheskii Zhurnal $\mathbf{4 1} 80$

7. Han H S, Jiang S N, Huang M Y and Jiang Y Y 1996 Polym. Adv. Technol. 7704

8. Yin M Y, Yuan G K, Wu Y Q, Huang M Y and Jiang Y Y 1999 J. Mol. Catal. A: Chem. 14793
9. Zhao C Z, Egashira N and Ohga K 1998 Anal. Sci. 14 439

10. Jinrui X and Bin L 1994 Analyst 1191599

11. Ye X, Yang Q, Wang Y and Li N 1998 Talanta 47 1099

12. Cruz J, Kawasaki M and Gorski W 2000 Anal. Chem. 72680

13. Zhang M and Gorski W 2005 Anal. Chem. 773960

14. Chen L and Gorski W 2001 Anal. Chem. 732862

15. Zhang M, Smith A and Gorski W 2004 Anal. Chem. 765045

16. Wei X, Cruz J and Gorski W 2002 Anal. Chem. 74 5039

17. dos Santos D S, Riul A, Malmegrim R R, Fonseca F J and Oliveira O N, Lattoso L H C 2003 Macromol. Biosci. 3591

18. Wang $Y$, Zhu J, Zhu R, Zhu Z, Lai Z and Chen Z 2003 Meas. Sci. Technol. 14831

19. Wang H S, Pan Q X and Wang G X 2005 Sensors 5 266

20. Riccardo A, Muzzarelli A and Rocchetti R 1974 Talanta 211137

21. Lu G, Yao X, Wu X and Zhan T 2001 Microchem. J. 6981

22. Wan Ngah W S and Musa A 1998 J. Appl. Polym. Sci. 692305

23. Zhao C, Pan Y, He C, Guo Z and Sun L 2003 Anal. Sci. 19607

24. Xin Y, Guanghan L, Xiaogang W and Tong Z 2001 Electroanalysis 13923

25. Schmuhl R, Krieg H M and Keizer K 2001 Water SA 271

26. Kamiñski W and Modrzejewska Z 1997 Sep. Sci. Technol. 322659

27. Wang R M, Xie X, Wang J Q, Pan S J, Wang Y P and Xia C G 2004 Polym. Adv. Technol. 1552

28. Roberts G A F 1992 Chitin Chemistry (London: MacMillan)

29. Gibbs G, Tobin J M and Guibal E 2004 Ind. Eng. Chem. Res. 431

30. Gibbs G, Tobin J M and Guibal E $2003 \mathrm{~J}$. Appl. Pol. Sci. 901073

31. Maruyama J and Abe I 2001 Electrochim. Acta 46 3381

32. Rodriguez J M D, Melina J A H and Pena J P $2000 \mathrm{~J}$. Chem. Ed. 91195

33. Cogo L C, Batisti M V, Pereira-da-Silva M A, Oliveira O N, Nart F C and Huguenin F $2006 \mathrm{~J}$. Power Sources 158160

34. Miller J N and Miller J C 2005 Statistics and chemometrics for analytical chemistry, Fifth edition (England: Prentice Hall, Harlow)

35. Lamy C, Lima A, LeRhum V, Delime F, Coutanceau $\mathrm{C}$ and Leger J M 2002 J. Power Sources 105283

36. Vielstich W 1965 Fuel cells: Modern processes for the electrochemical production of energy (New Delhi: Wiley-Interscience)

37. Xu Y, Amini A and Schell M 1994 J. Phys. Chem. 98 12759 